\title{
Una dosis única de rifampicina es efectiva para prevenir el contagio en contactos de pacientes con lepra recientemente diagnosticada
}

Single dose rifampicine is useful for preventing leprosy in close contacts of patients with newly diagnosed disease

Moet F y col. BMJ 2008; 336; 761-764

\section{Objetivo}

Determinar la efectividad de la quimioprofilaxis de una única dosis única de rifampicina para prevenir lepra en contactos cercanos.

\section{Diseño y lugar}

Ensayo clínico controlado aleatorizado doble ciego con un seguimiento promedio de cuatro años en dos distritos del nordeste de Bangladesh, en el contexto de un programa gubernamental de control de la lepra.

\section{Pacientes}

21.711 pacientes de ambos sexos, de un total 28.092 contactos cercanos de 1037 casos de lepra recientemente diagnosticada y definida por la presencia de al menos uno de los siguientes criterios: lesión cutánea compatible con lepra acompañada de déficit sensitivo, engrosamiento de un nervio periférico o bacilo ácido resistente documentado en un extendido de piel. El 7,5\% era familiar de primer grado del caso índice, presentando un $42 \%$ algún grado más alejado de parentesco. Respecto de su distancia física, solo el $8,5 \%$ era conviviente, siendo la mayoría vecinos o contacto sociales.

\section{Intervención}

Se aleatorizó a los contactos de pacientes con lepra reciente- mente diagnosticada a recibir una dosis de rifampicina o placebo a partir del segundo mes de tratamiento del paciente índice.

\section{Medición de resultados principales}

Desarrollo de lepra clínicamente evidente en los contactos de los pacientes índice*, con análisis por intención de tratar*.

\section{Resultados principales}

Durante los primeros dos años de seguimiento una dosis única de rifampicina se asoció a una reducción global de la incidencia* de lepra de $57 \%$ (IC95\% 33 a $72 \%$ ) reduciéndose un $34,9 \%$ (IC95\% 9.8-53\%) la incidencia de nuevos casos de lepra durante cuatro años de seguimiento. Fue necesario tratar 265 (NNT*) contactos para prevenir un caso adicional de lepra a los dos años (IC 95\% 176-537) y 297 (IC95\% 170 a 1206) si el este horizonte se extiendo a cuatro años.

\section{Conclusiones}

La quimioprofilaxis con una dosis única de rifampicina de los contactos cercanos de pacientes con lepra recientemente diagnosticada, es efectiva para prevenir el desarrollo de lepra a dos años.

Palabras claves: quimioprofilaxis en lepra, contactos de lepra, incidencia, rifampicina. Key words: leprosy chemo-prophylaxis, leprosy contacts, incidence, rifampicine. Fuente de financiamiento: No referida.

\section{Comentario}

La lepra es una enfermedad infectocontagiosa endémica en todos los continentes salvo en la Antártida, predominando en países en desarrollo, y encontrándose las dos terceras partes de los casos en Asia y particularmente en la India. Su prevalencia es alta en América Latina, principalmente Brasil, México, Noreste argentino (Formosa, Chaco y Misiones) y Republica Dominicana. Si bien en los últimos 30 años hubo una tendencia sostenida a la reducción de su incidencia en todo el mundo, en Africa, Asia y América Latina continúa siendo un problema de salud pública. En el año 1970 se identifico la primera droga bactericida contra el M. Leprae: la Rifampcina, que hoy es el pilar del tratamiento. A partir de la década del ochenta el tratamiento y hasta la actualidad es de elección el tratamiento con tres drogas: dapsona, clofazimina y rifampicina.

Todavía no existe una vacuna efectiva contra la lepra y su presentación clínica está en relación con el estado inmunológico del huesped. La probabilidad de contagio depende de la distancia física, de la edad del contacto y del parentesco genético entre éste y el caso índice. La quimioprofilaxis con dapsona tiene una eficacia del $60 \%$ para prevenir lepra en los contactos ${ }^{1,2}$ pero tiene la desventaja de que requiere un tratamiento muy largo, potencialmente toxico generador de resistencia. La rifampicina es un potente bactericida contra el M. Leprae, requiere dosis menores y menor tiempo de administración que dapsona. Por ejemplo, un estudio no controlado, recientemente realizado en Indonesia reportó que dos dosis de rifampicina con un intervalo de tres meses tienen una eficacia de 40 a $50 \%$ para prevenir el contagio ${ }^{3}$.

El estudio que resumimos demuestra que una única dosis de rifampicina administrada a los contactos de pacientes con lepra recientemente diagnosticada puede reducir significativamente el riesgo de que desarrollen lepra, observándose claramente este beneficio, durante por lo menos los primeros dos años de seguimiento.

Este estudio tiene la ventaja de haber incluido un gran número de pacientes y haberlos seguido durante cuatro años, pero al haberse llevado a cabo en una región de alta incidencia de lepra no queda claro si sus resultados pueden extrapolarse a nuestra población.

\section{Conclusión de la comentadora}

La administración de una única dosis de rifampicina a los contactos de pacientes con diagnóstico reciente de lepra sería una práctica sencilla, barata y efectiva. Sin embargo, hacen falta nuevos estudios y durante períodos más prolongados.

Ver glosario*

Noelia Capellato [ Servicio de Medicina Familiar y Comunitaria del Hospital Italiano de Buenos Aires. noelia.capellato@ hospitalitaliano.org.ar ]

Recibido el 02/06/08 y aceptado el 22/07/08

Capellato. N. Una dosis única de rifampicina es efectiva para prevenir el contagio en contactos de pacientes con lepra recientemente diagnosticada. Evid. actual. práct. ambul; 11(4):102, Jul-Ago.2008. Una dosis única de rifampicina es efectiva para prevenir el contagio en contactos de pacientes con lepra recientemente diagnosticada. Comentado de: Moet $\mathbf{F}$ y col. Effectiviness of single dose rifampicine in preventing leprosy in closer contacts of patients with newly diagnosed leprosy: clusted randomized controlled trial. BMJ 2008; 336; 761-764. PMID: 18332051. Disponible en URL: http://www.bmj.com/cgi/reprint/336/7647/761 (último acceso 21/07/08).

Referencia

1. Noordeen S y col. Chemoprophylaxis among contacts of nonlepromatous leprosy. Lepr India 1976;48(4 suppl):635-42.

2. NoordeenSK.Longtermeffectsof chemoprophylaxisamongcontacts of lepromatous cases. Results of 8 1/2 years follow-up. Lepr India 1977;49:504-9.

3. Cartel JL, et al. Chemoprophylaxis of leprosy with a single dose of $25 \mathrm{mg}$ per kg rifampin in the southern Marquesas; results after four years. Int $\mathrm{J}$ Lepr Other Mycobact Dis 1992;60:416-20. 